\section{Sequential study of bone mineral density in patients with systemic lupus erythematosus}

A loss of bone mineral density has been reported $^{1-3}$ in premenopausal women with systemic lupus erythematosus (SLE), but its pathogenesis is uncertain. ${ }^{4}$ Studies on the sequential changes in bone mass in these patients are scarce. ${ }^{35}$

Recently, we studied 74 premenopausal women with SLE without any complications or treatment (except for glucocorticoids) that could interfere with bone mineral density. We excluded nine osteoporotic patients according the established World Health Organisation criteria, ${ }^{6}$ because they were on treatment for low bone density. We repeated the measurement of bone mass after 18 months in 25 consecutive patients, all of whom had continued on glucocorticoid treatment during this period.

Bone mineral density was measured in the lumbar spine (L2-L4) and femoral neck (FN) by dual energy $x$ ray absorptiometry (DXA), using a densitometer (Hologic QDR 1000). Measurement of the bone mineral content, calibrating with the Hologic X-calibre QDR-1 anthropomorphic spine phantom of the known mineral content, was accurate to $0.5 \%$. The precision measurement was better than $0.01 \mathrm{~g} \mathrm{~cm}^{-2}$ (coefficient of variation $=1.0 \%$ at bone mineral density $\left.1.0 \mathrm{~g} \mathrm{~cm}^{-2}\right)$. Disease activity was assessed with the University College Hospital/Middlesex SLE scoring system, ${ }^{7}$ by a numerical score graded from 1 to 4 (inactive to severely active disease).

The results were expressed as the mean (SD). For all conventional analyses we used the SPSS/PC software package. A $t$ test was used and the correlations were calculated by linear regression analysis. Results were considered significant at $\mathrm{P}<0.05$.

At the time of the first densitometry, the mean age was $31.7(6.8)$ years, and disease duration was 91 (64) months.

After 18 months there was no significant decrease in bone mineral density, despite glucocorticoid treatment (table), in either the lumbar spine or the femoral neck. No fractures were found. Serum calcium, phosphorus, creatinine, and alkaline phosphatase, and 24 hour urine calcium and phosphorus did not change during this period.

Using linear regression, there was no correlation between bone mineral density or changes in bone mineral density and the prednisone dose (cumulative and baseline) We found no correlation between disease duration or mean disease activity grade and bone mineral density. No other correlations with bone mineral density were found.

This study shows that in premenopausal SLE patients lumbar and femoral bone min-

Characteristics of 25 patients at baseline and after 18 month

\begin{tabular}{lll}
\hline & $\begin{array}{l}\text { Baseline (mean } \\
(S D))\end{array}$ & $\begin{array}{l}18 \text { months } \\
(\text { mean }(S D))\end{array}$ \\
\hline L2-L4 $\left(\mathrm{g} \mathrm{cm}^{-2}\right)$ & $1.00(0.09)$ & $1.00(0.1)^{\star}$ \\
F.neck $\left(\mathrm{g} \mathrm{cm}^{-2}\right)$ & $0.80(0.07)$ & $0.79(0.08)^{\star}$ \\
P.baseline (mg) & $17(2)$ & $16(9.4)$ \\
P.cumulative (g) & $35(2)$ & $41(5)$ \\
Activity grade & $2.47(0.4)$ & $2.41(0.5)$ \\
\hline
\end{tabular}

^ All $P$ values $>0.05$ versus baseline. eral density did not change with respect to baseline values after 18 months, despite continuous glucocorticoid treatment (the mean dose was $9.2 \mathrm{mg} /$ day during the 18 months). Recently, Pons et al ${ }^{3}$ reported similar results in a study of 31 premenopausal women followed for a mean of 36.6 months. Kalla $e$ $a^{5}$ also found no changes in bone mineral density in 56 SLE patients over 18 months.

The effect of glucocorticoids on SLE osteoporosis is controversial. ${ }^{1-3}$ We did not find any correlation between prednisone dose and bone mineral density in chronic steroid users. The effects of glucocorticoids on the bone mass are most pronounced early in the course of steroid treatment. ${ }^{89}$ These data may partly explain our results. Also, a multifactorial action could explain the lack of correlation between the dose of glucorticoids and bone mineral density. Glucocorticoids may paradoxically inhibit bone resorption that has been stimulated by $\mathrm{PGE}_{2}$ or cytokines. ${ }^{1011}$

In conclusion, after 18 months there were no significant decreases in bone mineral density in premenopausal SLE patients on glucocorticoid treatment. The reported reduction in bone mineral density in these patients may occur at the onset of the disease. Nevertheless, future studies to demonstrate small loss of bone mineral density in SLE will probably require more patients and a longer period of study.

F FORMIGA

J M NOLLA I MOGA

D ROIG-ESCOFET

Internal Medicine and Rheumatology Service, Hospital "Princeps d'Espanya", CSU de Bellvitge,

L'Hospitalet de Llobregat, Barcelona, Spain.

1 Kalla AA, Fataar AB, Jessop SJ, Bewerunge L Loss of trabecular bone mineral density in systemic lupus erythematosus. Arthritis Rheum 1993;36:1726-34

2 Formiga F, Moga I, Nolla JM, Pac M, Mitjavila F, Roig-Escofet D. Loss of bone mineral density in premenopausal women with systemic lupus erythematosus. Ann Rheum Dis 1995; 54:274-6.

3 Pons F, Peris P, Guañabens N, Font J, Huguet $M$, Espinosa $G$, et al. The effect of systemic M, Espinosa $G$, et al. The effect of systemic lupus erythematosus and long-term steroid therapy on bone mass in pre-menop
women. $B r f$ Rheumatol $1995 ; 34: 742-6$

4 Dhillon VB, Davies MC, Hall ML, Round JM Ell PJ, Jacobs HS, et al. Assessment of the effect of oral corticosteroids on bone mineral density in systemic lupus erythematosus: a preliminary study with dual energy $x$ ray absorptiometry. Ann Rheum Dis 1990;49:624 6.

5 Kalla A, Bewerunge L, Swanelvelder S, Meyers OL, Fataar AB. Lack of corticosteroid effect on trabecular bone density over 18 months in systemic lupus erythematosus. Arthritis Rheum 1995;38:S359.

6 World Health Organisation. Assessment of fracture risk and its application to screening for postmenopausal osteoporosis. WHO Technical Report Series, No 843. Geneva: WHO, 1994.

7 Isenberg DA, Shoenfeld Y, Schwartz RS. Multiple serologic reactions and their relationship to ple serologic reactions and their relationship to clinical activity in systemic lupus erythe
sus. Arthritis Rheum 1984;27:132-8.

8 LoCascio V, Bonuci E, Imbimbo B, et al. Bone loss after glucocorticoid therapy. Calcif Tissu Int 1984;36:435-8.

9 Rickers H, Deding A, Christiansen C, et al. Mineral loss in cortical and trabecular bone during high-dose prednisone treatment. Calcif Tissue Int 1984;36:269-72.

10 Lukert BP, Raisz LG. Glucocorticoid-induced osteoporosis: pathogenesis and management. Ann Intern Med 1990;112:352-64.

11 Manolagas SC, RL Jilka. Bone marrow, cytokines, and bone remodeling. Emerging insights into pathophysiology of osteoporosis. N Engl f Med 1995;332:305-11.

\section{MATTERS ARISING}

\section{Unilateral Heberden's \\ nodes in a case of Erb-Duchenne paralysis}

Referring to the letter by Etherington and Spector " Asymmetrical nodular osteoarthritis in a patient with a hemiparesis", Annals of the Rheumatic Diseases, November 1995, p 936), we would like to offer a contribution based on our recent experience.

Although Stecher and Karnosh ${ }^{1}$ assert that apparent involution of Heberden's nodes on the hemiplegic side should be attributed exclusively to the effects of a reduction of soft tissues, in spite of the existence of $x$ ray nodes, Forestier, ${ }^{2}$ Hench and McEwen, ${ }^{3}$ and Thompson and Bywaters ${ }^{4}$ suggest a "neurogenic protection" against nodes on the affected side.

This particular characteristic of Heberden's and Bouchard's nodes, was pointed ou both in hemiplegic subjects following a central cerebral lesion - as in the case of Etherington and Spector ${ }^{5}$-or in upper limbs affected by peripheral paralysis (obstetric paralysis or traumatic interruption of a nerve).

Our case is a 45 year old female who presented with Erb-Duchenne paralysis and Heberden's nodes limited to the healthy side, while the affected arm shows a lack of musculoskeletal development (radius, ulna, carpus, metacarpus, and phalanges) (figure)

In analogy with what has been pointed out in the case of rheumatoid arthritis and hemiplegia $^{67}$ it is possible formulate several hypotheses:

(1) A protective action of central or peripheral neurological lesions with respect to osteoarthritic or arthritic manifestations on the affected side, through interruption of the central reflex arc, which is responsible for the symmetric lesions in rheumatoid arthritis and osteoarthrosis.

(2) Attenuation of superimposed inflammation in osteoarthrosis by the conditioning of the biochemical expression of the neurogenic inflammation (mediated by substance $P$, a neuropeptide which acts specifically at low concentrations on "formyl peptide" receptors; this leads to the activation of polymorphonuclear cells and is present both early and in large quantities in inflammed synovium).

(3) Not be ignored, in our opinion, is the physiological decline of the proprioception in subjects of advancing age ${ }^{10}$ and the absence of the normal proprioceptive stimuli linked to the "microtraumatic" use of the hands which is limited only to the affected hand. Such absence is also presumably responsible for lack of node production related to enthesitic ossification at the distal phalanx level.

We agree with Etherington and Spector about the possibility that several valid concepts relating to the protective effects of neurological lesions, either central or periph- 


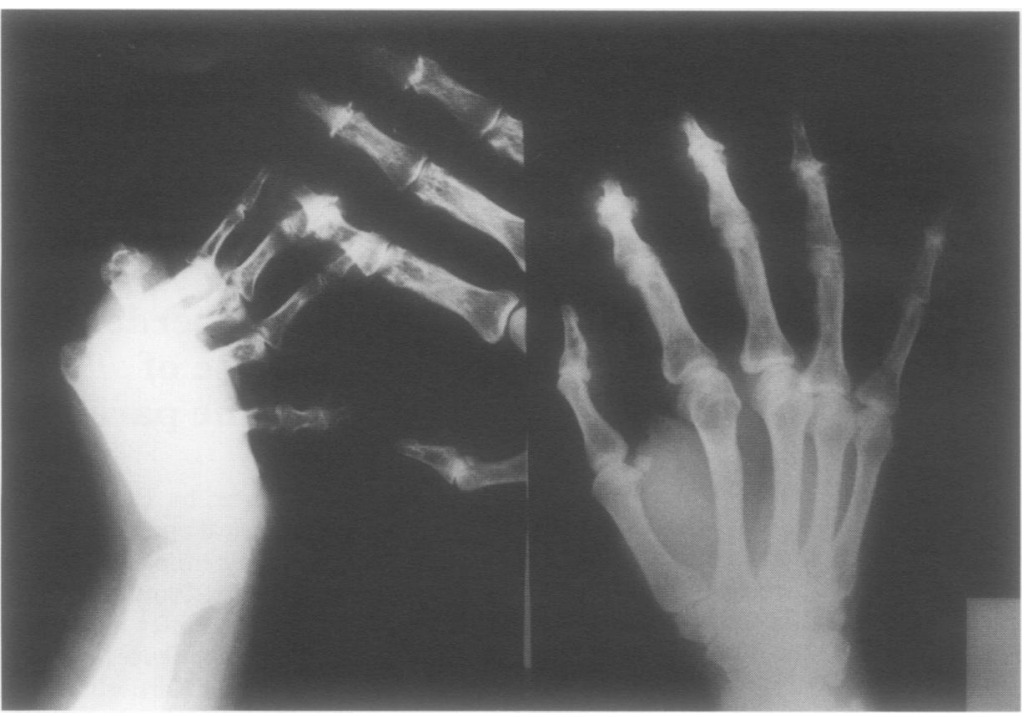

$X$ ray examination of the hands shows, on the left side, underdevelopment of the bones of the carpus, metacarpus, and phalanges without osteodegenerative lesions of the distal interphalangeal joints; Heberden's nodes are present on the right side.

eral, in rheumatoid arthritis are equally applicable on the appearance of Heberden's and Bouchard's nodes.

\section{ZORZIN}

$M$ L SORGI

G PALOMBI

Institute of Rheumatology, "La Sapienza" University, Policlinico "Umberto I", Viale del Policlinico, Rome, Italy

1 Stecher RM, Karnosh LJ. In: Thompson $M$ Bywaters EGL. Unilateral rheumatoid arthritis following hemiplegia. Ann Rheum Dis 1962; 21:370-7.

2 Forestier J. Rhumatisme d'Heberden chez un hémiplégique: lésions articulaires limitées au côté sain. Rev Neurol 1935;63:442-4.

3 Hench PS, McEwen C. Heberden's nodes: heredity in hypertrophic arthritis of the finger joints. $\mathcal{F} A M A$ 1940;115:2024-5.

4 Thompson M, Bywaters EGL. Unilateral rheumatoid arthritis following hemiplegia. Ann Rheum Dis 1962;21:370-7.

5 Etherington J, Spector TD. Asymmetrical nodular osteoarthritis in a patient with a hemiparesis. Ann Rheum Dis 1995;11:936-7.

6 Levine J, Collier D, Basbaum A, Moskowitz M, Helms C. Hypotesis: the nervous system may contribute to the pathophysiology of rheum toid arthritis. $\mathcal{F}$ Rheumatol 1985;12:406-11.

7 Levine J, Daedick S, Roizen M, Helms C, Basbaum $A$. Contribution of sensory afferents and sympathetic afferents to joint injury in experimental arthritis. $\mathcal{F}$ Neurosci 1986;6:3423-9.

8 Lembeck F, Donnerer J, Colpaert F. Increase of substance $P$ in primary afferent nerves during chronic pain. Neuropeptides 1981;1:175-80.

9 Skinner H, Barrack R, Cook S. Age-related decline in proprioception. Clin Orthop 1984; 184:208-11.
10 Lience E, Ros C, Sellas A, Arderiu A. Rheumatoid arthritis and hemiplegia: remission of the arthritis in the paretic limbs and appearance of a subcutaneous nodule in the non paretic elbow. Med Clin (Barc) 1993;101:518-9.

\section{Camptocormia or cormoptosis? The etymology of the word}

We read with interest the recent Lesson of the Month that "not all stoops are due to osteoporosis". It is now clear that camptocormia of the elderly ${ }^{2-4}$ is a different clinical entity from the syndrome seen in the first world war which affected military recruits and was generally regarded as a psychogenic disorder. ${ }^{56}$ The word "camptocormia" has been used to describe both clinical disorders interchangeably. Though recently French authors have proposed alternative terms such as "muscular insufficiency" and "proklinorachie", 8 these also fail to distinguish between the two groups.

During the last five years we have seen four cases (all female, mean age 66.5 years) who presented with painless spinal stoop. The diagnosis of "camptocormia in the elderly" was made on the basis of the typical posture with characteristic anterior curvature of the spine ("ptosis") which disappeared completely when the patient assumed the supine position. They were asymptomatic for back pain. There was no neurological deficit or psychiatric disturbance. The computer tomography (CT) scan of the thoracolumbar spine showed diffuse atrophy of the paraspinal muscles and heterogeneity of signal with areas consistent with increased water content; however, the CT findings in this condition are difficult to interpret and there is some debate about the range normality in the elderly. Electromyography of the lumbar paraspinal and other muscles revealed a myopathic pattern. Muscle biopsy was not performed as no subject agreed to this procedure.

We propose that the term "cormoptosis" should be used for the clinical picture of painless stoop in the elderly. The word derives from the Greek word cormos (meaning body or trunk) and ptosis (meaning passive movement downward: exactly the picture seen in this disorder). The word "camptocormia" includes the Greek word campto meaning to bend forward actively, which is what is seen in military recruits who have what is essentially a psychogenic disorder. The " $p$ " in cormoptosis as well in apoptosis should be pronounced. "Proclinorachie" has the similar meaning in Greek, as the word camptocormia. ${ }^{6}$

Therefore we propose to reserve the term "camptocormia" for the hysterical stoop and introduce the term "cormoptosis" for the stoop presenting in the elderly when other neurological disorders have been excluded.

DIMITRIOS KARRAS Department of Rheumatology, NIMTS, Athens, Greece

JOHN VASSILAKOS DIMITRIOS KASSIMOS

401 Military Hospital of Athens, Messogion Av Athens, Greece

1 Ehrenstein MR, Stoll T, Edwards JCW. Not al stoops are due to osteoporosis. Ann Rheum Dis 1996;55:21-3.

2 Laroche M, Delishe MB, Aziza R, Lagarrique J, Mazieres B. Is camptocormia a primar muscular disease? Spine 1995;20:1011-6.

3 Laroche M, Delishe MB. La camptocormie primitive est une myopathie para-vertébrale. Rev Rhum [Engl Ed] 1994;61:419-22.

4 Hilliquin P, Menkes CJ, Laoussadi S, JobDesandre C, Serratrice G. Camptocormie du suget âgé. Une nouvell entité par atteinte des muscles paravertébraux? Rev Rhum Mal Ostemuscles paravertébraux?

5 Hurst AF. The bent back of soldiers. BMF 1918;ii:621-3.

6 Clervoy P, Corcos M, Devillieres P. De cire et de plâtre... Les camptocormies du Val-de-Grâce. La Revue Du Praticien 1996;46:284-6.

7 Poullin P, Daumen-Lagre V, Serratrice G. La camptocormie du sujet âgé: Myopathie ou dystonie musculaire? Rev Rhum [Ed Fr] 1993; 60:159-61.

8 Renie JC. Cyphose réductible, camptocormie proclinorachie. Rev Rhum [Ed Fr] 1992; 59:169-75. 